\title{
Carolina de Jesus em Caruaru e Recife: \\ Racismo Estrutural e Imprensa no Início dos Anos 60
}

OLIVEIRA, Raphael Alberti Nóbrega de ${ }^{1}$

\section{RESUMO}

Artigo que intenciona desvelar a visita de Carolina de Jesus, em Caruaru, fazendo uma discussão historiográfica sobre os livros Quarto de despejo, Casa de Alvenaria e matérias do jornal Diário de Pernambuco sobre a vinda da escritora na Capital do Agreste, em 1960.

Carolina de Jesus. Negritude. Racismo. Caruaru. Nordeste brasileiro.

\section{Carolina de Jesus in Caruaru and Recife: Structural Racism and the Press in the early 60s}

\section{ABSTRACT}

Article that intends to reveal the visit of Carolina de Jesus, in Caruaru, making a historiographical discussion about the books Quarto de despejo, Casa de Alvenaria and articles from the newspaper Diário de Pernambuco about the writer's arrival in the Caruaru, in 1960.

Carolina de Jesus. Blackness. Racism. Caruaru. Brazilian Northeast.

\section{Carolina de Jesus en Caruaru y Recife: racismo estructural y la prensa a principios de los años 60}

\section{RESUMEN}

Artículo que pretende desvelar la visita de Carolina de Jesús, en Caruaru, haciendo una discusión historiográfica sobre los libros Quarto de Espelho, Casa de Alvenaria y artículos del periódico Diário de Pernambuco sobre la llegada de la escritora a la Capital do Agreste, en 1960.

Carolina de Jesus. Negritud. Racismo. Caruaru. Nordeste Brasileño.

\section{Carolina de Jesus in Caruaru e Recife: Razzismo Strutturale E Stampa Nei Primi Anni '60}

\footnotetext{
${ }^{1}$ Mestre em História, Política e Bens Culturais pelo Centro de Pesquisa e Documentação de História Contemporânea do Brasil da Fundação Getúlio Vargas (CPDOC/FGV-RJ). Professor de História da Escola em Tempo Integral Rubem de Lima Barros, em Cidade Jardim - Caruaru. E-mail: raphalberti@gmail.com. Lattes: http://lattes.cnpq.br/3066918719265320. Orcid: https://orcid.org/0000-0002-4663-7117.

REVISTA

interritórios

Interritórios | Revista de Educação Universidade Federal de Pernambuco, Caruaru, BRASIL | V.6 N.11 [2020]
} 


\section{RIASSUNTO}

Articolo che intende rivelare la visita di Carolina de Jesus, a Caruaru, facendo una discussione storiografica sui libri Quarto de evpejo, Casa de Alvenaria e articoli del quotidiano Diário de Pernambuco sull'arrivo dello scrittore nella Capitale di Agreste, nel 1960.

Carolina de Jesus. Nero. Razzismo. Caruaru. Nord-est Brasiliano.

\section{INTRODUÇÃO}

O quão paradoxal pode ser a constatação que uma das maiores escritoras de todos os tempos de um país é ao mesmo tempo uma das mais esquecidas, menos divulgadas e mais desrespeitadas pelas elites intelectuais desse mesmo território? Quando se trata de um país patriarcal, machista, racista e misógino como o Brasil, esta frase não se mostra tão antagônica.

Carolina Maria de Jesus, mãe solteira de três filhos, moradora de favela, negra e com apenas dois anos presentes em uma escola é uma das maiores vendedoras de livros da história do Brasil. Já foi traduzida para treze idiomas e vendeu mais de um milhão de cópias de seus livros. Chamada por alguns especialistas de precursora da literatura marginal, influenciou gerações com sua "escrita verdadeira", como bem colocou Clarice Lispector. ${ }^{2}$ Deu cor a fome (amarela) e refutou condutas tidas como padrão, mesmo quando esteve inserida no meio das classes médias e elites. Por isso, foi negligenciada pela mídia e governos a partir do seu segundo livro Casa de Alvenaria, publicado em 1961. Suas origens da pobreza, negritude e linguajar coloquial foram fatores decisivos para este tipo de tratamento.

Carolina de Jesus nasceu em Sacramento (MG), em 1914. Com vinte e três anos de idade mudou-se para a capital paulista, após a morte da mãe e teve graves problemas financeiros, que culminaram dez anos depois na sua ida para a favela do Canindé (SP). Desempregada e grávida, catava papéis, latas, papelões para conseguir sustentar seus filhos. Das revistas e papéis que coletava dos lixões, transformava em fonte de leitura e escrita de seu diário, que retratava a vida de uma moradora de favela, seus atores sociais, a violência doméstica, a miséria e principalmente a fome, que é a protagonista do livro Quarto de despejo.

Com a ida do jornalista da revista $O$ Cruzeiro, Audálio Dantas, à favela para fazer uma reportagem sobre sua expansão para as margens do Rio Tietê ocorreu o encontro com a escritora mineira. Audálio ficou encantado com a

2 Revista Manchete, agosto de 1961. 
escrita do diário e não só a ajudou a publicá-lo como se colocou com um tutor na divulgação e administração dos rendimentos conseguidos com o livro.

Quarto de Despejo, publicado em 1960, foi um sucesso e em uma semana vendeu 10 mil exemplares. A sua trajetória de divulgação do livro por várias cidades brasileiras e sua transição da favela para uma casa foram os cenários para a escrita de Casa de Alvenaria de 1961. Este livro não fez tanto sucesso quanto o primeiro e gerou críticas pouco construtivas e associações indevidas à Carolina de Jesus. Em Casa de Alvenaria, a escritora conta sua passagem por Pernambuco, começando no Recife, passando por Caruaru e retornando a capital pernambucana, no final de 1960.

No ofício de historiador progressista, sempre me senti na obrigação de preencher minha formação acadêmica com leituras periféricas e publicar trabalhos voltados para uma visão anticolonial, antirracista e antissistêmica. $\mathrm{Na}$ minha visão, capitalismo e democracia são duas palavras opostas e um dos "filhos" deste sistema é o racismo. É o racismo que sustenta privilégios e dá aval para etnocentrismos e dominações políticas, culturais e econômicas de brancos contra negros, de ocidentais contra orientais, de colonizadores contra povos originários.

Sou fã de Carolina de Jesus desde que assisti um desfile da escola de samba Renascer de Jacarepaguá, em 2017. O enredo "O papel e o mar" contava a história do encontro fictício entre Carolina de Jesus (o papel) e João Cândido (o mar), líder da Revolta da Chibata, em 1910. ${ }^{3}$ Li Quarto de despejo e Casa de Alvenaria e notei nesse último livro lido, que havia um relato de uma visita de Carolina em Caruaru, cidade que atualmente moro e que possui uma séria deficiência de arquivos que guardem a memória da cidade.

Sendo assim, pesquisei na Hemeroteca Digital da Biblioteca Nacional reportagens sobre a cobertura da vinda da escritora para Pernambuco, em dezembro de 1960. Divulguei nas redes sociais uma matéria sobre a passagem da escritora por Caruaru e em parceria com o jornalista Lafaete Vaz do G1, surgiu a ideia de publicar uma matéria na imprensa local, tanto escrita quanto televisiva, valorizando personalidades negras esquecidas na História e suas percepções sobre Caruaru.

Com este artigo pretendo revisitar esta passagem de Carolina por Pernambuco, traçando comparativos com suas obras e fazendo uma análise do discurso da imprensa sobre este momento. Além disso, procurarei problematizar a temática do racismo utilizando referências na causa antirracista como Angela Davis e Silvio Almeida. Discutirei as várias facetas do racismo estrutural, a fetichização do negro pelas elites, preconceito linguístico e as tentativas de

\footnotetext{
${ }^{3}$ Liga da Escolas de Samba do Rio de Janeiro. Renascer de Jacarepaguá, Carnaval de 2017. Disponível em: http://lierj.com.br/portfolio-item/renascer-de-jacarepagua/. Acesso em: 24 de junho de 2020.
} 
cooptação de Carolina de Jesus por esferas ideológicas antagônicas no contexto da Guerra Fria.

\section{Análise Documental}

A cobertura da visita de Carolina de Jesus em Pernambuco, pelo Diário de Pernambuco durou oito dias. ${ }^{4}$ É relevante destacar o espaço que Carolina ganhava no jornal devido a sua chegada. No período citado, Carolina já tinha renome nacional e poderia perfeitamente ao longo desses dias estampar as capas do jornal. Isto só ocorre uma vez, em 14 de dezembro de 1960. Além disso, o jornalista Celso Rodrigues revelou que o universitário Hugo Gomes avisou o jornal $A$ Voz do Agreste dos planos de Carolina ir para Caruaru e de um possível destaque na imprensa local. A resposta foi negativa, pois a redação iria publicar seis matérias sobre as atividades parlamentares do deputado Tabosa de Almeida. ${ }^{5}$

Podemos relacionar esta situação de exposição tímida de sua presença no estado de Pernambuco com o conceito de racismo estrutural que permeia as esferas política, econômica e social, enraizando e naturalizando a discriminação dos negros no sistema capitalista brasileiro. O racismo estrutural atua consciente e inconscientemente, fazendo com que pessoas não se preocupem em usar termos pejorativos ao se referir aos negros, a tratar como algo corriqueiro a baixa presença de profissionais negros no setor da comunicação, educação superior, política, entre outros (ALMEIDA, 2018). Será que a imprensa daria o mesmo tratamento para uma autora branca famosa como Zélia Gattai, que vendeu menos livros do que Carolina de Jesus ${ }^{6}$ e em 2001, foi eleita para a Academia Brasileira de Letras? Tenho certeza que não.

Carolina de Jesus desembarcou no Aeroporto dos Guararapes, em Recife no dia 13 de dezembro de 1960 e esteve na capital também nos dias 14 e 16 de dezembro participando de tarde de autógrafos na Livraria Editora Nacional e encontro com o prefeito Miguel Arraes. Somente no dia 15 de dezembro de 1960 iria se dirigir para Caruaru (JESUS, 1961).

\footnotetext{
${ }^{4}$ Do dia 11 a 18 de dezembro de 1960.

${ }^{5}$ Diário de Pernambuco, 13 de dezembro de 1960.

${ }^{6}$ O livro mais famoso de Zélia Gattai, Anarquistas, graças a Deus vendeu 200 mil cópias. Quarto de despejo vendeu 1 milhão de exemplares. O Estado de São Paulo. Zélia Gattai, fotógrafa sim, graças a Deus. Disponível em: https://cultura.estadao.com.br/noticias/artes,zeliagattai-fotografa-sim-gracas-a-deus,38702. Acesso em: 24 de junho de 2020.
}

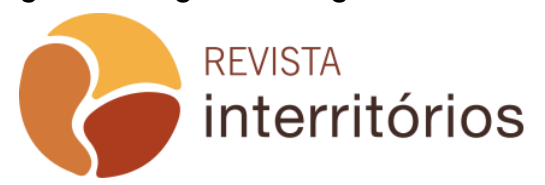


Figura 1: Carolina de Jesus autografa seu livro Quarto de despejo para a socialite Miss Mary Johnson, com sua filha encarando o fotógrafo, representando o futuro, a nova geração

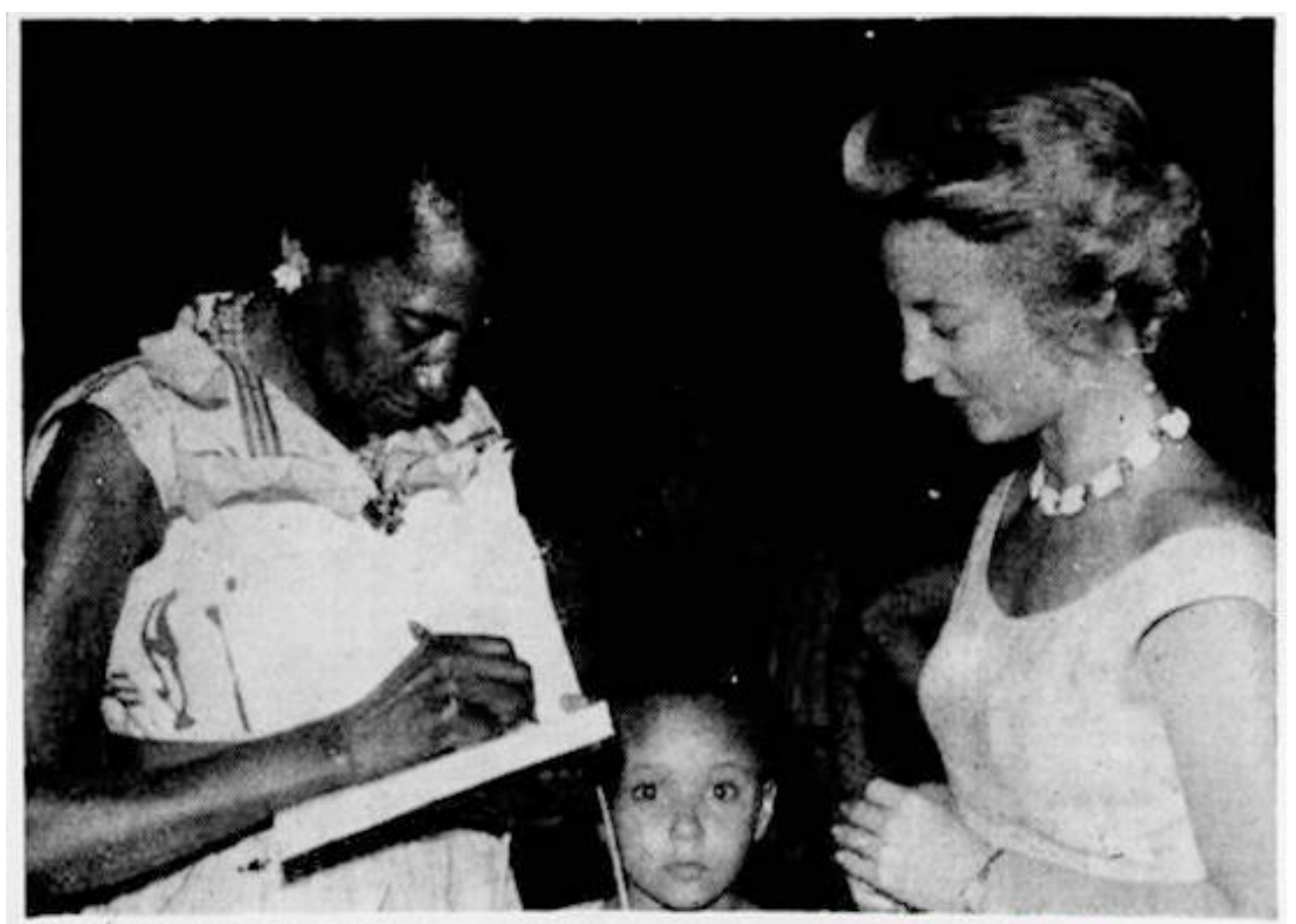

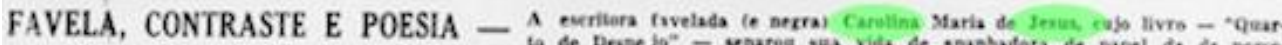

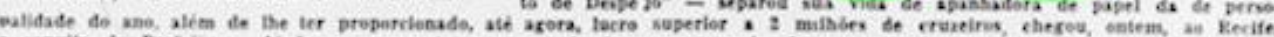

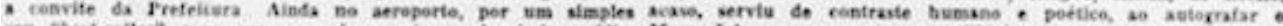

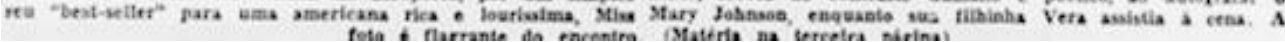

Fonte: Diário de Pernambuco, 14 de dezembro de 1960.

De acordo com o livro Casa de Alvenaria, a escritora levantou-se às seis da manhã para esperar a Kombi que a levaria até a Capital do Agreste, junto com Audálio Dantas. O transporte só chegou às 09:00 para levá-la à Caruaru com o motorista e o repórter Joacir Fonseca Soares, que caiu no gosto de Carolina por sua "alegria, bom humor e inteligência" (JESUS, 1961). Iria se hospedar no Hotel Centenário ${ }^{7}$ quando chegasse e autografar livros na Barraca Nacionalista.

Ela elogiou a rodovia asfaltada que liga Recife à Capital do Forró e reparou que nos jardins colocaram plantas que suportavam as altas temperaturas, mas que não eram coloridas. Exceto o flamboyant que dava lindas flores vermelhas. Percebeu no olhar dos pernambucanos o quanto olhavam este

\footnotetext{
${ }^{7}$ Atual Center Plaza Hotel. Rua 7 de setembro, 84, Bairro Nossa Senhora das Dores. 
cenário com ternura. Ficou bem sensibilizada com a situação de miséria dos pernambucanos ao ver casebres humildes e pessoas raquíticas no caminho: "Fiquei pensando: até na Natureza há seleções. No Sul chove, no Norte não" (JESUS, 1961).

Figura 2: Carolina de Jesus autografando livros na capital pernambucana em 1960.

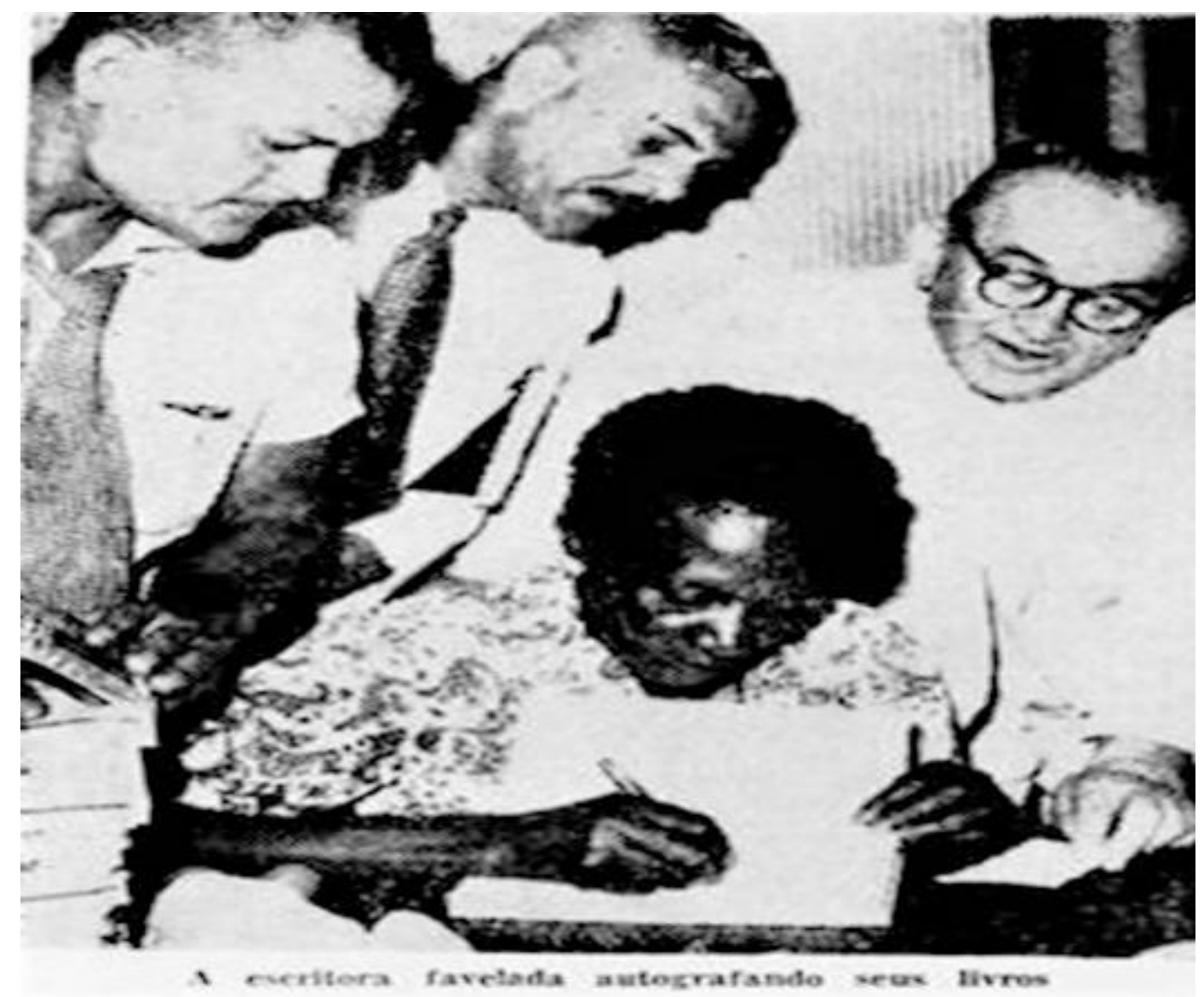

Fonte: Diário de Pernambuco, 15 de dezembro de 1960.

"Pretinha, risonha e desembaraçada" 8 foi desta forma que o jornalista Celso Rodrigues do Diário de Pernambuco descreveu Carolina Maria de Jesus em Caruaru. Com tantos adjetivos para caracterizar uma das maiores vendedoras de livros do Brasil, o jornalista se viu na necessidade de descrever sua negritude no diminutivo, como se sua posição na sociedade como pessoa negra fosse objeto de piedade, inferiorizando-a. O "desembaraçada" assume uma conotação burlesca de sua desenvoltura na fala e ações, como se não esperasse que alguém naquelas condições pudesse ser tão sagaz. Pode parecer um mero detalhe, mas as palavras usadas para retratar personalidades negras, revelam o quanto a questão racial no país precisava entrar como pauta

${ }^{8}$ Diário de Pernambuco, 18 de dezembro de 1960.

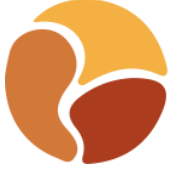


formativa para profissionais da comunicação. São termos que machucam, desqualificam e marcam a trajetória de uma pessoa.

Voltando a questão do racismo estrutural, seria impensável que jornalistas se referirem a uma escritora branca como Clarice Lispector, que estivesse lançando livros em uma cidade do interior do Nordeste, como "branquinha, sorridente e desembaraçada". Não quero com essa fala desconsiderar que existem outros meios de opressão como o machismo e misoginia que ofendem e diminuem o papel da mulher brasileira na sociedade que vivemos. Entretanto, é relevante situar que mulheres brancas e negras recebem tratamento diferenciado da imprensa, mesmo estando em uma posição profissional e social semelhantes. Isso precisa ser colocado e debatido se desejamos um país plural e democrático.

Sendo assim, é necessário demonstrar o quanto historicamente o racismo foi um poderoso instrumento para a manutenção de uma sociedade patriarcal no Brasil e no mundo. Negras escravizadas eram constantemente estupradas por senhores de engenho no período colonial e imperial. Desta forma, a filósofa Angela Davis aponta que os estupros cometidos por proprietários brancos em negras escravizadas, além do componente racial tinha anexado a questão econômica capitalista. Como os negros no período escravocrata estadunidense, e o mesmo pode ser apontado no Brasil colonial e imperial, não eram vistos como seres humanos com direitos iguais aos brancos, e sim tratados como mercadorias, procriar era sinônimo de lucro (DAVIS, 2016). Quanto mais filhos uma negra escravizada tivesse, mais negros poderiam ser vendidos no mercado escravista, futuramente. Quanto mais negros vendidos, maior poder aquisitivo tinha o latifundiário e isto fazia com que o patriarcado se fortalecesse.

Carolina de Jesus encantou-se com os caruaruenses. Foi anunciada por uma estação de rádio como hóspede oficial da municipalidade e percebeu o quão agradáveis eram os filhos da Capital do Agreste: "São tão delicados que não se nota o culto e o inculto" (JESUS, 1961). Porém, ficou com dó dos fãs caruaruenses que a receberam às $17: 00$ na Rua da Matriz, ${ }^{9}$ pois só havia 3 exemplares de Quarto de despejo para que ela os autografasse. ${ }^{10}$ Sendo assim, teve que assinar em livros de outros autores ${ }^{11}$ para não os decepcionar: "Fiquei com dó daquele povo. E pensei: eles gostam de ler e os livros chegam aqui com atraso. Gostam de lavouras, mas as chuvas são escassas" (JESUS, 1961) e "É um povo muito bom, mas triste. Está na hora de acabar com a miséria no Nordeste". ${ }^{12}$ Tratava os fãs com cordialidade: "O seu nome, por obséquio" e "Ao amigo/a com admiração de Carolina Maria de Jesus". ${ }^{13}$

\footnotetext{
9 Atual Avenida Rio Branco.

10 Diário de Pernambuco, 18 de dezembro de 1960.

11 Diário de Pernambuco, 17 de dezembro de 1960.

12 Diário de Pernambuco, 17 de dezembro de 1960.

13 Diário de Pernambuco, 15 de dezembro de 1960.
}

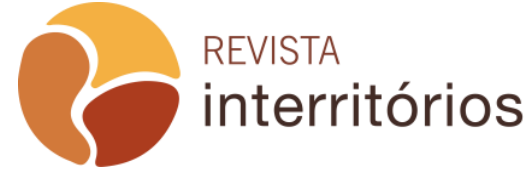

Interritórios | Revista de Educação Universidade Federal de Pernambuco, Caruaru, BRASIL | V.6 N.11 [2020] 


\section{A R U A R U}

\section{ADIADA PARA HOJE A VISITA DA ESCRITORA CAROLINA MARIA DE JESÚS}

Tarde de autografos, na rua da Matriz - Preparativos para ${ }^{70}$ a "Testa do Comércio" - Funcionários municipais fizeram curso na Fundação Getúlio Vargas - Política - Desportos Notas de Celso RODRIGUes

CARUARU - Um atraso verificado no aviáo em que viajava a escritora Carolina Maria de Jesús provocou o adiamento das homenagens que aquí seriam prestadas, terça-feira, à tarde, á autora de Quarto de Despejos.

Fôra anunciada uma tarde de autografos, na Barraca Nacionalista. O povo prestigiou a iniciqtiva, comparecendo ao local onde a escritora favelada teria contr. to com os caruaruenses. Quase is 18 horas foi confirmada a noticia de que Carolina adiara a visita para quinta-feira.

Déste modo, o mesmo progra- ta de uma pilhérias, E, como tal, de segunda-feira, quando seti náo pode ser levada a sério. * O vereador Severino Rodrigues, (Chico do Leite), a quem se atribulu a denúncia, apresso'sse, por sua vez, em fazer decla. raçóes ao DIARIO. Disse qua ca manchete sensacional do jor. nal eCorreio do Povo» não era de sua responsabilidades, co:2. cluindo:

¿Nunca autorizei a publicação de semelhante coisa. Qualquet declaraçáo politica que parta de mim terá a minha assinatura: só assim terá valôrs. veiculo fol atingido por um ca. minhăo sem frejos, na Serra das Russinhas, já voltou a suas atl. vidades, á frente da Festa do Comércio».

* O governador Cid Sampaio. nos próximos mèses, pretenrle iniciar sua primeira realizaçio em Caruaru - edificio do eCole. gio Estadual.

* Sobre o colégio, temos ainda a informar que a primeira etapa do Lia Salgado está pratica. mente concluida. 0 educandárı é amplo e atende às necessi. dades de Caruaru.

Fonte: Diário de Pernambuco, 15 de dezembro de 1960.

O descaso na divulgação de Quarto de Despejo em Caruaru, e a naturalização da falta de livros da autora negra como apenas um "descuido", revela uma das transformações do racismo nesse momento de transição da vida de Carolina de Jesus, período em que saía da classe baixa para uma classe média baixa ou classe média, pura e simples, por conta do sucesso de vendas do seu primeiro livro.

Apesar de não receber diretamente ofensas orais sobre sua negritude, evidentemente Carolina de Jesus não recebe o tratamento adequado para a ocasião. É possível imaginar os problemas que seriam criados por autores brancos de sucesso nacional se chegassem a uma cidade para o lançamento de seus respectivos livros e não tivesse exemplares suficientes? O quão ultrajados se sentiriam e o quanto isso poderia repercutir negativamente na imprensa? Por

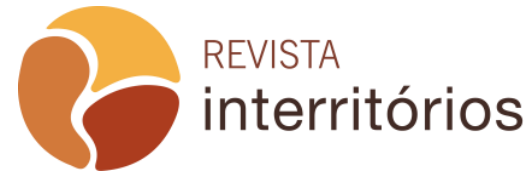


que em caso semelhante com uma escritora pobre e negra ocorreu uma naturalização deste procedimento?

Batista (2018) mostra esta reflexão sobre as formas de racismo cultural existentes no processo de ascensão social de negros. A própria Carolina de Jesus no começo de Casa de Alvenaria demonstra estar em processo de adaptação a transição social e também ao tratamento que as classes médias e elites dariam a ela como formadora de opinião: "Alguns críticos dizem que sou pernóstica quando escrevo. (...) Será que preconceito existe até na literatura? 0 negro não tem direito de pronunciar o clássico?" (JESUS, 1961. p. 63-64). Desta forma, Carolina pensava inicialmente, que o racismo era algo voltado especificamente para os negros favelados. A partir do momento que saísse daquela conjuntura, no instante em que fosse reconhecida como escritora a sua classe profissional e social não the trataria com preconceito, inferiorizando-a ou difamando-a.

Partindo dessa reflexão de Carolina sobre racismo na literatura, trago um acontecimento ocorrido após a sua morte que dialoga com esta questão. No dia 17 de abril de 2017, Carolina de Jesus foi homenageada na Academia Carioca de Letras. O professor de literatura Ivan Cavalcanti Proença começou elogiando a obra e levou um exemplar raro da obra Quarto de despejo de 1966. Porém, concluiu sua fala com as seguintes frases:

Só tem uma coisa, isso não é literatura. Isso pode ser um diário e há inclusive o gênero, mas definitivamente, isso não é literatura. Cheia de períodos curtos e pobres, Carolina sem ser imagética, semi-analfabeta, não era capaz de fazer orações subordinadas, por isso esses períodos curtos. (LUCINDA, 2017).

Esta fala evidencia vários aspectos do racismo estrutural, cobrando um formalismo na escrita de Carolina de Jesus para legitimá-la como autêntica escritora, como uma par. Desvela questionamentos sobre o fato de uma negra e periférica estar sendo homenageada no lugar literário mais prestigiado da cidade, como se aquele espaço não pertencesse a pessoas com aquelas características.

A resposta à Ivan Proença foi dada com classe pela poeta negra, Elisa Lucinda:

Se me perguntarem o que mais me incomoda no epidêmico e sistemático racismo, direi que é o olhar que depositam sobre nós a proferir as mesmas mudas perguntas: 'como ousas? O que você está fazendo aqui? Você não sabe que aqui não é o seu lugar?'. Sem flagrante aparente, mas intimidadora essa pergunta é feita com o olhar e não deixa dúvidas. Portanto, herdeira da 
coragem dessa mulher que no ano que nasci foi descoberta por escrever o seu olhar nos papéis que catava e os quais reciclava em cadernos, venho exaltar o seu escrito: 'quem inventou a fome, são os que comem'. 'Quem não tem amigo, mas tem um livro, tem uma estrada', 'Fiz o café e fui carregar água, olhei o céu a Estrela Dalva já estava. Como é horrível pisar na lama. As horas que sou feliz é quando estou residindo nos castelos imaginários'. Isso não é literatura? Me desculpe, senhor Ivan Cavalcante Proença, o que Carolina Maria de Jesus fez chamase Literatura e por isso estamos aqui, e por isso a tradução em tantas línguas, e por isso o maravilhoso livro Quarto de despejo que fez com que a referida autora fosse tema do Fórum das Letras de Ouro Preto, idealizado e concebido pela maravilhosa escritora Guiomar de Grammont, editora da melhor qualidade, conhecida como curadora de Feiras Literárias internacionais. Nesse fórum foi lançado um livro em sua homenagem: Memorialismo e Resistência- estudos sobre Carolina Maria de Jesus. (LUCINDA, 2017).

A colocação feita por Ivan Proença se mostra mais trágica e lamentável pela sua trajetória de militar progressista que atuou contra um cerco de outros militares a estudantes que protestavam na Faculdade de Direito da Universidade Federal do Rio de Janeiro (UFRJ), no dia 1 de abril de 1964, contra o golpe civilmilitar. ${ }^{14}$

Após o contato com os fãs, Carolina foi levada a um pátio (o atual Pátio de Eventos Luiz Gonzaga), onde o poeta Lycio Neves a recebeu todo trajado de um terno branco. Uma banda de forró animou o local com zabumbas que chamaram a atenção de Carolina. Notou também que os integrantes eram "pretos, mal vestidos e mal nutridos", assim como os moradores da favela do Canindé. Eles olhavam para Carolina com veneração. Um olhar terno e acolhedor que fez a escritora lhes dar mil cruzeiros.

Prepararam comes e bebes para sua chegada também. Carolina se impressionou com os bolos e bebidas. Apesar da escritora não mencionar o tipo de bebida, relatou que era gostosa, alcoólica e que só não bebeu mais, pois ficou com receio de embriagar-se e não cumprir suas obrigações oficiais na cidade (JESUS, 1961).

\footnotetext{
${ }^{14}$ Dicionário Cravo Albin da Música Popular Brasileira. Verbete: Ivan Proença. Publicado em Disponível em: http://dicionariompb.com.br/ivan-cavalcante-proenca/biografia. Acesso em: 23 de junho de 2020.
}

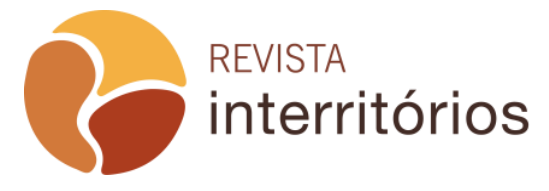


Figura 4: Reportagem narrando a trajetória de Carolina de Jesus em Caruaru com foco no seu discurso de despedida

\section{DIARIO DE PERNAMIBUCC-SABAIJO, 17 DE DEZEMBRO DE 19:0}

\section{CAROARO}

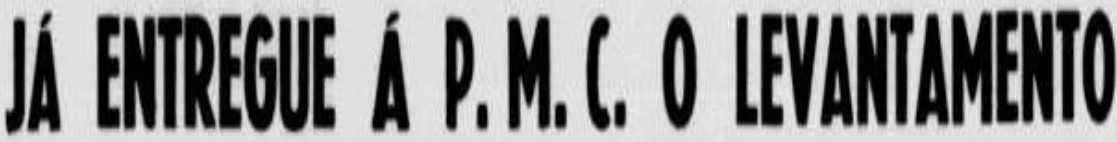

\section{AEROFOTOGRAMETRICO DE: CARUARU}

\section{A "Gruzeiro do Sul" recebeu 2 milhôes e 100 mil cruzeiros} - Trabalho de grande signilic açáa - Regozijo - Carolina Maria de Jesus, o acontecimento de quintadeira - 0 "Vsporte" jogaréc contra o "Central" - Politica Notas de Celso RODRIGUES

CARUARU - 0 st. Walter no Rio Grande do Sul so queria Recife, congratulando-se com 0 Brito, um dos diretores da Cru- que o senhor visses, zeiro do Sulb, aqui esteve, on- A noite, no Hotel Centenário, tem para entregar ao prefeito a escritora lol homenageada do municipio o levantamento com um jantar, ao qual compaaerofotogrametrico da cidade de receram intelectuais, o juiz Ama. Caruaru, que há dois anos vinha ro de tira e Cesar e o prefeito sendo feito por aquela organiza. Joáo Lyra Filho. cảo,

0

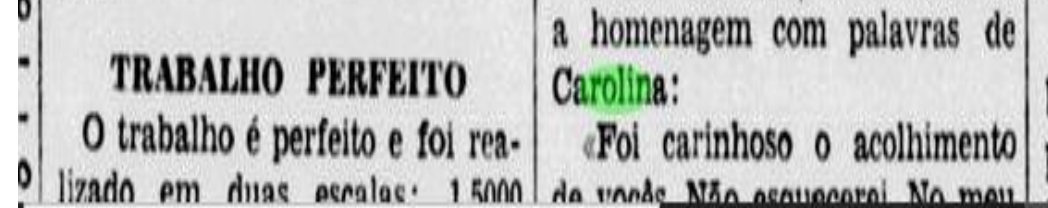
primeiro ano da sua administra. ção. As referencias teitas aqui, d conduta do sr. Miguel Arraes, à frente da Prefeitura do Recife. sáo as melhores possiveis; e og telegramas enviados ao chefe do Executivo recifense atestam essse houroso conceito.

* Carolina Maria de Jesus, abordada em Caruaru sobre os politicas nacionais, disse nåo gos.

Fonte: Diário de Pernambuco, 17 de dezembro de 1960.

À noite, jantou no Hotel Centenário com intelectuais, o prefeito João Lyra e o juiz Amaro de Lira e César. Ao todo eram 35 pessoas. Assim como ela, notou que o prefeito passou o jantar todo calado e na maior parte do tempo com os cotovelos na mesa e rosto apoiado nas

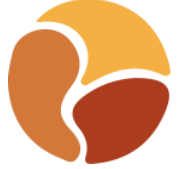


mãos, ouvindo os convidados criticarem outros políticos, menciona autora em Casa de Alvenaria. Já no Diário de Pernambuco, o jornalista Celso Rodrigues afirmou que João Lyra colheu boas impressões da escritora "com quem palestrou demoradamente". ${ }^{15}$ Carolina falou sobre sua impressão do prefeito, após ser fotografada com ele: "Parece ser um administrador bem intencionado. É de gente assim que precisamos". ${ }^{16}$ Completou:

"Foi carinhoso o acolhimento de vocês. Não esquecerei. No meu próximo livro despertarei a atenção dos políticos para os seus problemas - os problemas do Nordeste. Os presidentes só se lembram de São Paulo e do Rio. Fazem injustiças aos nordestinos. Vou dizer isso". (DIÁRIO DE PERNAMBUCO, $17 \mathrm{de}$ dezembro de 1960)

Figura 5: Jornalista refere-se a Carolina de Jesus como: "Pretinha, risonha e desembaraçada"

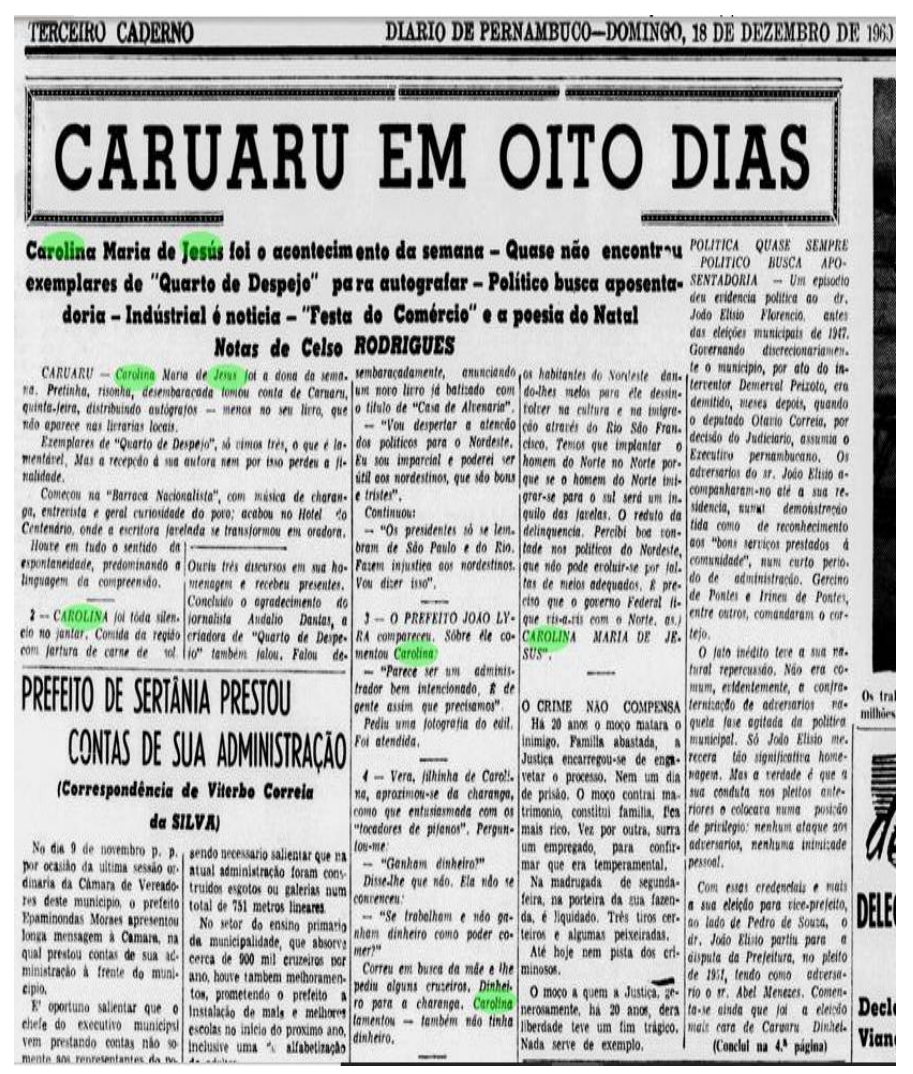

Fonte: Diário de Pernambuco, 18 de dezembro de 1960.

A escritora fez um discurso de 6 minutos prometendo denunciar em seu livro Casa de Alvenaria, os problemas que assolavam a região:

15 Diário de Pernambuco, 17 de dezembro de 1960.

16 Diário de Pernambuco, 18 de dezembro de 1960.

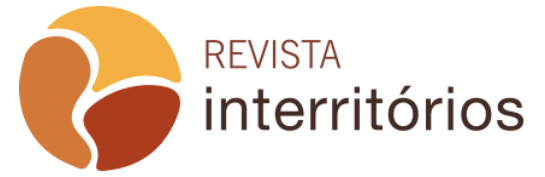

Interritórios | Revista de Educação Universidade Federal de Pernambuco, Caruaru, BRASIL | V.6 N.11 [2020] 
Visitando Caruaru a convite do ilustre prefeito senhor João Lyra Filho fiquei emocionada com a recepção. Vi a terra do ilustre escritor José Condé e o seu povo oprimido pela Natureza que sacrifica este recanto do Brasil. O povo é culto comprovando o que a maioria pensa a respeito do Nordestino que se ele tiver meios não mede esforços para ilustrar-se. O Nordestino no seu torrão, é cordial, culto e atencioso e suplanta o paulista na solidariedade. O desenvolvimento cultural do Nordestino contribuirá para desenvolver o seu estado. Com a condição deficiente do povo, o Estado não devia pagar imposto Federal. Será que o Governo Federal tem coragem de arrecadar imposto desse estado? A renda deve ficar no próprio estado para ser aplicada em benefício do povo. É preciso que o Governo Federal coopere com os habitantes do Nordeste dando-lhes meios para ele dessinvolver (sic) na cultura e na imigração através do Rio São Francisco. Temos que implantar o homem do Norte no Norte porque se o homem do Norte imigrar-se para o sul será um inquilino das favelas. $O$ reduto da delinquência. Percibi (sic) boa vontade nos políticos do Nordeste que não pode evoluir-se por falta de meios adequados. É preciso que o Governo Federal fique vis-a-vis com o Norte. (DIÁRIO DE PERNAMBUCO, 18 de dezembro de 1960).

Vale destacar o uso das palavras "dessinvolver" e "percibi". Muitas vezes, o desvio da norma culta da língua portuguesa é usado como forma de desmerecer e desconsiderar aquele que a utiliza. É uma prática corriqueira naqueles que fazem preconceito linguístico, conceito amplamente abordado pelo linguista da Universidade de Brasília (UNB), Marcos Bagno (1999). Apesar das ideias de Carolina de Jesus serem passadas de forma translúcida, há uma inclinação a deslegitimar sua opinião de boicote dos impostos pelo insuficiente retorno federal de investimentos em saúde, educação e infraestrutura na região, devido ao uso de vocábulos que não são utilizados na língua portuguesa formal. De forma alguma, quero insinuar que isso foi feito por jornalistas do Diário de Pernambuco, todavia é importante mostrar essa problematização que perpassa a trajetória de Carolina ao longo de sua carreira profissional.

Outro ponto marcante é o posicionamento de Carolina de Jesus sobre assuntos centrais da política nacional dos anos 60 , período de polarização ideológica dentro de um contexto da Guerra Fria. Apesar de não usar o termo Reforma Agrária, notoriamente apresenta uma posição favorável à redistribuição de terras no Brasil:

Ficava pensando: com tantas terras abandonadas e o povo passando fome! Essas terras pertencem aos capitalistas. Ninguém pode chegar e plantar algo sem o seu consentimento. Eles tem dinheiro para pagar a Dona Lei e suas confusões. $O$ mundo para sem bom é preciso que as terras sejam livres. $O$ homem poderá desfrutar a terra porque ela é inesgotável. As 
terras sendo livres, todos plantam e a miséria extingue-se. Um povo bem alimentado é um povo feliz. (...) Por que o governo não distribui terras para o povo? Eu penso isto, mas não digo porque se eu disser isto os capitalistas vão dizer: - A Carolina é vermelha. É ignorante e semi-analfabeta. (JESUS, 1961. p. 85).

Nota-se na fala de Carolina de Jesus, que a partir do instante em que se posiciona como sujeito político, opina e se coloca ao lado de pautas progressistas é imediatamente associada ao comunismo. Como se a defesa de pautas democráticas estivesse sempre associada ao rótulo da defesa da extinção das classes sociais. Paralelamente a isso, configurou-se uma queda no número de vendas do segundo para o primeiro livro e a falta de convites para matérias e aparições na imprensa. Também uma prática do racismo estrutural.

Carolina de Jesus era publicizada por parte da imprensa e bajulada por certos expoentes das elites na divulgação de Quarto de despejo como um viés de fetichização do negro na sociedade. Era confortável para esses atores sociais mostrarem como ela representa um exemplo da eficácia da meritocracia, veiculando a mensagem de que basta se esforçar individualmente para ascender socialmente. Muitas das socialites que se aproximavam de Carolina em locais públicos o faziam como forma de melhorar suas imagens na mídia e foram criticadas em Casa de Alvenaria pela escritora. No dia 09 de novembro de 1960, Carolina de Jesus foi jantar com o senhor Ferrão, após uma noite de autógrafos na Feira do Livro, na Cinelândia, Rio de Janeiro: "No restaurante nós escolhemos o que comer. Eu fiquei horrorizada porque as madames jogavam metade das comidas fora. E no preço que está (sic) os gêneros alimentícios!" (JESUS, 1961).

Carolina também critica neste livro o excesso de comidas nas festas com tantas pessoas morrendo de fome no país. Esses comentários enfureceram pessoas com alto poder financeiro e influenciou diretamente no tratamento da imprensa ao seu segundo livro. É como se houvesse uma permissão social para a negra falar sobre a favela e a pobreza, mas ao mesmo tempo, um veto para negros que passassem a pertencer a classe média e quisessem dar suas contribuições no campo da política. Como se não permitissem suas críticas ao sistema capitalista e tivesse que demonstrar apenas gratidão e docilidade a partir de agora. Como se a conquista individual fosse suficiente para Carolina. Não era e nunca será para uma pessoa que se enxergava como cidadã, parte de um todo complexo e com a dimensão da responsabilidade dos seus atos. 
Figura 6: 0 apoio de Carolina de Jesus ao Hospital do Câncer, em Recife

\section{FALAM OS ESCRITORES:}

CEIIO MHIRA:

O amor a nossor imionos, e prinstpalmente, a nosyos irmáos enferitios - E O PÃO DIVINO DAS ALMAS, Quando socotremos os docntes, no ubismo dos solrimeatos, adubamos, $\mathrm{cm}$ no. me do Mestre, reflorcscimento de esperanģas",

CAROLINA MARIA DE JESLS:

Nós que estamos shios temos cbrigaglio de aju. dat os que crtio docates?

AJUDE A CAMPANHA CONTRA O CANCER, comprando bilhetes do sorteio de Aero-Willys, 196!.

(*) - A escritora favelada, Carolina Maria de Jesus comprou os bilhetes 2151 e 2152 .

Fonte: Diário de Pernambuco, 18 de dezembro de 1960.

No fim do jantar, Carolina de Jesus ganhou do Mestre Vitalino alguns bonecos de argila e o que ela mais gostou foi o denominado: "O Jornalista". ${ }^{17}$ Carolina de Jesus se despediu de Caruaru em direção à Recife no dia seguinte, 16 de dezembro de 1960. Saiu pedindo desculpas à Juscelino Kubitschek, alvo de suas críticas em "Quarto de despejo", por ela ter notado canos adutores que levavam água para Caruaru de uma distância de 40 quilômetros. Em Recife, visitou o Hospital do Câncer e ficou tão sensibilizada com a condições dos

17 Diário de Pernambuco, 15 de dezembro de 1960.

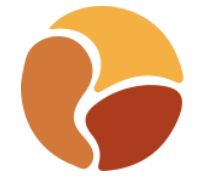


pacientes que entrou em campanhas que arrecadaram doações para 0 hospital. ${ }^{18}$

\section{Considerações Finais}

Carolina de Jesus em Pernambuco é um microcosmo das relações étnicoraciais do Brasil, dos anos 1960. Ela é a exceção que conseguiu sobreviver a miséria, a fome, ao racismo e ao machismo. Em um mundo bipolar da Guerra Fria, onde países e pessoas deviam se enquadrar ao lado capitalista ou socialista, Carolina acabou sendo cooptada pelos dois blocos.

Por um lado, ela serve como "prova" para os liberais que com muito esforço e dedicação todos podem conseguir uma condição financeira melhor. Quarto de despejo é visto por conservadores como uma experiência antropológica que atrai por ser vista de longe, sem interação com as classes baixas e a protagonista em seus momentos difíceis. Já os progressistas procuravam encaixá-la na órbita socialista pelas denúncias às mazelas sociais, ao empoderamento da negritude e a crítica ao sistema capitalista que gera a pobreza para que uma minoria abastada se beneficie dela com excesso de mãode-obra, pagamento de baixos salários e manutenção do status quo de uma camada social branca, elitista e racista.

Percebe-se que Casa de Alvenaria não fez o mesmo sucesso de Quarto de despejo devido a um sistema sócio-político impregnado pelo racismo estrutural que se incomoda ao ver uma pessoa negra emancipada socialmente, emitindo críticas sobre a postura das elites em festas, cerimônias e relações interpessoais. Um sistema que se coloca como perfeito e imputa culpa dos seus problemas nos indivíduos. Uma sociedade que deseja ver os negros com posturas dóceis e fragilizados pela miséria nas favelas. As críticas feitas à Carolina taxando-a de agitadora social, são velhas demonstrações de um reacionarismo que defende seus privilégios econômicos e sociais contra qualquer um que apoie medidas igualitárias no campo, na educação e na política.

Quarto de despejo teve a importância de ser o relato da vida de uma habitante de favela pela própria moradora. Com sua fala peculiar, seu olhar de indignação para a indiferença de empresários e governantes e a colocação da fome como protagonista do diário de uma pessoa atraiu a atenção de governantes e intelectuais para a compra e aproximação da escritora. Carolina de Jesus divulgou-o em Recife, Caruaru, Mogi das Cruzes, Porto Alegre, Rio de Janeiro e dialogou com figuras como Eduardo Suplicy, Leonel Brizola, Miguel Arraes, Clarice Lispector e Jorge Amado. Até uma peça denominada Quarto de

18 Diário de Pernambuco, 18 de dezembro de 1960. 
despejo foi encenada em homenagem a escritora pela atriz Ruth de Souza (JESUS, 1961).

O racismo estrutural presente em todos os pilares da estrutura sóciopolítica brasileira é identificado na imprensa pernambucana com uso de termos pejorativos e silenciamentos. Mesmo a fama de Carolina de Jesus na época não foi o suficiente para sofrer com descasos de tratamento como figura importante da literatura brasileira. Apesar de ter sido recebida de forma cordial e amistosa pelos cidadãos caruaruenses, era merecido um destaque maior nos jornais e 0 descarte de adjetivos que inferiorizaram Carolina de Jesus por conta de sua negritude.

\section{REFERÊNCIAS}

ALMEIDA, Silvio Luiz de. O que é racismo estrutural? Belo Horizonte (MG): Letramento, 2018.

BAGNO, Marcos. Preconceito linguístico: O que é? Como se faz? São Paulo: Edições Loyola, 1999.

BATISTA, Waleska Miguel; MASTRODI, Josué. "Dos fundamentos extraeconômicos do racismo no Brasil". Revista Direito e Práxis, Ahead of print, 2018. Disponível em: http://www.e-publicacoes.uerj.br/index.php/revistaceaju/article/view/30077. Acesso em: 22 de junho 2020. DOI: 10.1590/2179-8966/2018/30077

DAVIS, Angela. Mulheres, raça e classe. São Paulo: Boitempo, 2016.

Dicionário Cravo Albin da Música Popular Brasileira. Verbete: Ivan Proença. Publicado em Disponível em: http://dicionariompb.com.br/ivan-cavalcante-proenca/biografia. Acesso em: 23 de junho de 2020.

JESUS, Carolina Maria de. Casa de Alvenaria: diário de uma ex-favelada. São Paulo: Francisco Alves, 1961.

JESUS, Carolina Maria de. Quarto de despejo: diário de uma favelada. São Paulo: Francisco Alves, 1960.

LUCINDA, Elisa. Carolina de Jesus é literatura sim! Publicado em 24 de abril de 2017. Disponível em: https://www.publishnews.com.br/materias/2017/04/24/carolina-dejesus-e-literatura-sim. Acesso em: 23 de junho de 2020.

Diário de Pernambuco, dezembro de 1960. 